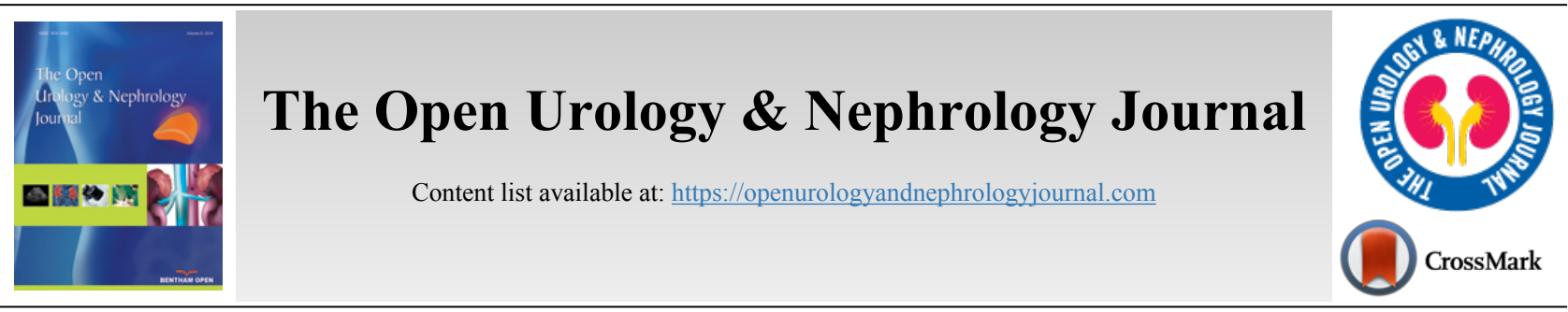

RESEARCH ARTICLE

\title{
Evaluation of Human Chorionic Gonadotropin (HCG) Therapeutic Results in Patients With Unilateral cryptorchidism (Undescended Testis)
}

Farzaneh Sharifiaghdas ${ }^{1}$, Sepideh Sharifiaghdas ${ }^{2}$, Esmaeil R. Maleki ${ }^{1}$, Behzad Narouie ${ }^{3,^{*}}$, Abdolsamad Shikhzadeh ${ }^{1}$ and Sarvenaz Mehrabi ${ }^{4}$

'Department of Urology, Urology and Nephrology Research Center, Shahid Labbafinejad Medical Center, Shahid Beheshti University of Medical Sciences, Tehran, Iran

${ }^{2}$ Department of Pediatrics, Torfeh General Hospital, Tehran, Iran

${ }^{3}$ Department of Urology, Zahedan University of Medical Sciences, Zahedan, Iran

${ }^{4}$ Department of Emergency, School of Medicine, Arak University of Medical Sciences, Arak, Iran

\section{Abstract: \\ Background:}

Cryptorchidism or undescended testis is an evolutionary defect where one or both testes fail to descend into the scrotum. HCG causes the testes to fail, possibly due to weight gain, an increase in testicular vasculature, and stimulating the testosterone and di-hydro-testosterone. The present study has been conducted to evaluate the therapeutic effects of HCG on patients with unilateral cryptorchidism.

Methods:

In a prospective descriptive study, 211 patients of 8 months to 7 years old with unilateral cryptorchidism whose parents refused surgery received HCG therapy. The patients were followed up 1 month, 3 months, and 12 months after the first injection. They were examined in terms of the location of testes, possible relapses, sides of undescended testes, treatment complications, and HCG therapeutic results.

Results:

Four weeks after the first injection, 160 patients $(75.12 \%)$ out of 211 cases had the descent of testes into the inguinal canal and the scrotum. $69.5 \%$ of non-palpable abdominal testes descended into the inguinal canal, $69.7 \%$ of patients with inguinal testes, $78 \%$ of patients with supra inguinal testes and $100 \%$ of patients with retractile testis experienced the descent of testes into the scrotum.

\section{Conclusion:}

The therapeutic response to HCG was successful in more than $50 \%$ of the cases in all the groups. Therefore, the need for performing surgical procedures on children with unilateral cryptorchidism would be decreased and they can be treated by a cost-effective and less invasive method. Moreover, at least one-year follow-up of the patients is required to ensure outcomes of the treatment.

Keywords: Cryptorchidism, HCG, Undescended testis, Pediatric urology, Therapeutic response, Invasive method.

\begin{tabular}{|l|l|l|l}
\hline Article History & Received: December 03, 2019 & Revised: March 09, 2020 & Accepted: March 10, 2020
\end{tabular}

\section{INTRODUCTION}

Cryptorchidism or undescended testis is an evolutionary defect where one or both testes fail to descend into the scrotum $[1,2]$. However, the prevalence of cryptorchidism is different in every country; it is $2 \%$ to $4 \%$ at birth and less than $1 \%$ after the first year of life [1 - 3]. Cryptorchidism is undiagnosed in

\footnotetext{
"Address correspondence to this author at the Department of Urology, Zahedan University of Medical Sciences, Zahedan, Iran, Tel: +989391837853; Email: b_narouie@yahoo.com
}

$2 \%$ to $5 \%$ of term male infants and more than $30 \%$ of premature males at birth [4 - 6]. The defect is more prevalent in the left testis and it is bilateral in $10 \%$ of the involved infants [7 - 9]. The undescended testis can be located outside the external ring (supra scrotal), in the inguinal canal, or the abdomen [10]. Genetic predispositions, preterm birth, low birth weight, and parents' exposure to hormonal disorders or tobacco are the major risk factors for cryptorchidism [11 - 14].

Although the main reason behind cryptorchidism is not clear, it probably occurs due to the hormonal impairment or the 
presence of strands that block the path and consequently, testes remain in the inguinal canal. This condition can usually be treated with surgery or hormone therapy before puberty [15 $19]$.

Cryptorchidism can cause several complications, including hernia and torsion, infertility, testicular tumor, low selfconfidence, and disorders of sex development if it is not treated. People with cryptorchidism are at a higher risk of testicular cancer (5\%) compared to the general population. The best way to diagnose cryptorchidism is by taking clinical exams $[1,5,16,20,21]$.

Surgery is the gold standard treatment for cryptorchidism [22]. There are also different protocols for hormone therapy, such as injection of HCG, HMG (Menotropins), GnRH(Gonadotropin Release Hormone) agonists, and testosterone [23]. The therapeutic response is less than $30 \%$, depending on the disorder being unilateral or bilateral and the age of patients [20].

Human chorionic gonadotropin (HCG) is produced by the placenta in pregnant women and plays an important role in the continuation of pregnancy. It leads to the stimulation of progesterone secretion. Also, HCG is used for the treatment and the diagnosis of premature cryptorchidism caused by an anatomical obstruction $[2,23]$. This hormone causes the testes to fall, possibly due to weight gain, an increase in testicular vasculature, and stimulating the testosterone and di-hydrotestosterone [23]. Hormone therapy improves the histopathology of testes without damaging germ cells, which is estimated to be effective in $20-25 \%$ of the cases $[24,25]$. But, most studies showed that the apoptosis process would be intensified in germ cells immediately after the injection of HCG in boys with cryptorchidism [26, 27]. The present study has been conducted to evaluate the therapeutic effects of HCG on patients with unilateral cryptorchidism.

\section{MATERIALS AND METHODS}

In a prospective descriptive study, 211 patients with unilateral cryptorchidism who admitted to Shahid Labbafinejad, Milad, and Torfeh hospitals from 2012 to 2016 were investigated through consecutive and available sampling. The data were collected through clinical history, clinical examinations, ultrasonography, and a registration form. The case groups included boys from 8 months to 7 years old with unilateral cryptorchidism whose parents refused surgery; there- fore, HCG injection was considered as a treatment for the children. Ultrasonography was performed for all the cases of non-palpable testes (either abdominal or inguinal). The patients were divided into 4 groups based on the location of the testes, including non-palpable testes (abdominal), inguinal, palpable on the supra inguinal pouch (sup.ing) surface, and retractile testes. HCG was injected to the patients three times a week, in a 3-week period. The patients with a weight of less than $20 \mathrm{~kg}$ (57 cases) received 750 units of HCG and those with weights of $20 \mathrm{~kg}$ and more (154 cases) received 1500 units of HCG in 9 intramuscular injections at a two-day interval. The patients were followed up 1 month, 3 months, and 12 months after the first injection. They were examined in terms of the location of testes, possible relapses, sides of undescended testes, treatment complications, and HCG therapeutic results (a decline, a need for treatment with orchiopexy or laparoscopy). The collected data were analyzed using SPSS, descriptive statistics (frequency and percentage), and the chi-square test.

\section{RESULTS}

The study population included 211 boys from 8 months to 7 years old with the mean age of $18.6 \pm 8.3$ months with unilateral cryptorchidism whose parents refused the surgery. All the patients with unilateral cryptorchidism who were admitted to Shahid Labbafinejad, Milad and Torfeh hospitals got evaluated and were divided into 4 groups. (Table 1).

During the therapeutic period, the only significant complications were the engorgement of the penis and an occasional change in its color (pink or red) that made the parents worried. Different degrees of these short-term complications were observed in all the patients. They were visited by physicians 1 month, 3 months and 12 months after the first injection.

\subsection{The One-month Follow-up:}

A month after the first injection, the examinations revealed that 32 out of 46 patients $(69.5 \%)$ with abdominal testes had the descent of testes into the inguinal canal. Among 86 patients with inguinal testes, the testes descended to the scrotum in 60 of them (69.7\%). From 50 patients with sup.Ing(supra inguinal) testes, the testes descended to the scrotum in $39(78 \%)$ of them. Finally, the testes descended to the scrotum in $100 \%$ of the patients with retractile testes (Table 2).

The numbers of patients who referred for their follow-up visits after 3 months and a year are listed in Table 3.

Table 1. The frequency of cryptorchidism (undescended testis) in terms of location and side in patients with unilateral cryptorchidism.

\begin{tabular}{|l|c|c|c|c|c|c|}
\hline \multirow{2}{*}{-} & \multicolumn{2}{|c|}{ Right } & \multicolumn{2}{c|}{ Left } & \multicolumn{2}{c|}{ Total } \\
\cline { 2 - 7 } & Number & Percentage & Number & Percentage & Number & Percentage \\
\hline Abdominal & 26 & 56.5 & 20 & 43.5 & 46 & 21.8 \\
\hline Inguinal & 47 & 54.4 & 39 & 45.3 & 86 & 40.7 \\
\hline Sup.Ing & 23 & 46 & 27 & 44 & 50 & 23.6 \\
\hline Retractile & 10 & 34.4 & 19 & 65.6 & 29 & 12.3 \\
\hline
\end{tabular}


Table 2. The number of testes descended 4 weeks after HCG therapy in patients with unilateral cryptorchidism.

\begin{tabular}{|l|c|c|c|c|c|c|c|}
\hline \multirow{2}{*}{-} & \multicolumn{2}{|c|}{ Descended } & \multicolumn{2}{c|}{ Undescended } & \multicolumn{2}{c|}{ Total } & Both sides \\
\cline { 2 - 9 } & Right & Left & Right & Left & Right & Left & \\
\hline Abdominal & 18 & 14 & 8 & 6 & 26 & 20 & 46 \\
\hline Inguinal & 36 & 24 & 11 & 15 & 47 & 39 & 86 \\
\hline Sup.Ing & 19 & 20 & 4 & 7 & 23 & 27 & 50 \\
\hline Retractile & 10 & 19 & 0 & 0 & 10 & 19 & 29 \\
\hline Total & 83 & 77 & 23 & 28 & 106 & 105 & 211 \\
\hline Total of both sides & \multicolumn{2}{|l|}{160} & \multicolumn{2}{|c|}{211} & & \\
\hline
\end{tabular}

Table 3. The number of patients referred back during the follow-up period based on the response to HCG, in children with unilateral cryptorchidism.

\begin{tabular}{|c|c|c|c|c|}
\hline- & Abdominal & Inguinal & Supra Inguinal & Retractile \\
\hline Referred patients in $3^{\text {rd }}$ month & 24 & 63 & 33 & 20 \\
\hline Referred patients in $12^{\text {th }}$ month & 21 & 48 & 28 & 16 \\
\hline
\end{tabular}

Table 4. The impact of HCG on the descent of the testis based on the initial position of the testis and its recurrence rate.

\begin{tabular}{|c|c|c|c|c|}
\hline- & Anatomical Relocation ( $4^{\text {th }}$ week) & $\begin{array}{l}\text { Recurrence Rate }\left(3^{\text {rd }} \text { and } 12^{\text {th }}\right. \\
\text { months })\end{array}$ & Side & Follow-up Period \\
\hline \multirow[t]{2}{*}{ Abdominal } & \multirow[t]{2}{*}{$70 \%$ into inguinal canal (orchiopexy) } & \multirow[t]{2}{*}{$\begin{array}{ll}----- \\
-1\end{array}$} & Right: $70 \%$ & \multirow[t]{2}{*}{$4^{\text {th }}$ week: $70 \%$} \\
\hline & & & Left: $70 \%$ & \\
\hline \multirow[t]{3}{*}{ Inguinal } & \multirow[t]{3}{*}{$69 \%$ into scrotum } & \multirow[t]{3}{*}{$14.5 \%$} & \multirow[t]{2}{*}{ Right: $76 \%$} & $4^{\text {th }}$ week: $69 \%$ \\
\hline & & & & $3^{\text {rd }}$ month: $83 \%$ \\
\hline & & & Left: $62 \%$ & $12^{\text {th }}$ month: $88 \%$ \\
\hline \multirow[t]{3}{*}{ Supra inguinal pouch } & \multirow[t]{3}{*}{$78 \%$ into scrotum } & \multirow[t]{3}{*}{$15 \%$} & \multirow[t]{2}{*}{ Right: $82 \%$} & $4^{\text {th }}$ week: $78 \%$ \\
\hline & & & & $3^{\text {rd }}$ month: $96 \%$ \\
\hline & & & Left: $74 \%$ & $12^{\text {th }}$ month: $74 \%$ \\
\hline \multirow[t]{3}{*}{ Retractile } & \multirow[t]{3}{*}{$100 \%$ into scrotum } & \multirow[t]{3}{*}{$5 \%$} & Right: $100 \%$ & $4^{\text {th }}$ week: $100 \%$ \\
\hline & & & \multirow{2}{*}{ Left: $100 \%$} & $3^{\text {rd }}$ month: $90 \%$ \\
\hline & & & & $12^{\text {th }}$ month: $100 \%$ \\
\hline
\end{tabular}

\subsection{The 3-Month Follow-up:}

Three months after HCG therapy, 24 out of 35 patients with abdominal testis who had undergone orchiopexy $(22$ individuals) or laparoscopy ( 2 individuals) referred to the hospitals. The testes were palpable in 21 of them and were located in the scrotum in 15 patients. There were also suprascrotal testes in 6 cases. Moreover, 3 patients had very small nodule-like testicular tissues on the top of the scrotum and were diagnosed with severe atrophy based on the ultrasound's results.

Among 86 patients with inguinal testes, 63 of them referred to the hospitals to attend their 3-month follow-ups visits. 46 of them responded to HCG and the testes descended into the scrotum. Out of these 46 subjects, 38 cases experienced the full descent and testes in 8 cases descended to the sup.ing pouch surface; orchiopexy was done for these 8 patients as well. Out of 26 cases who did not respond to HCG and experienced orchiopexy, 17 individuals referred back again. The testes shrank to a smaller size than the opposite testis and were palpable within the scrotum in 15 of them. The other 2 patients were diagnosed with severe atrophy by ultrasound.

Among 49 patients with sup.ing testis who responded to HCG, 33 of them intended their 3-month follow-ups meetings and the testes were located in the scrotum in 32 of them. In one patient, the testis was occasionally suprascrotal and retractile; however, his problem was resolved by orchiopexy. From the other 11 patients who did not respond to $\mathrm{HCG}$ and underwent orchiopexy, 7 patients referred to the hospitals. The testes were located in the scrotum in all of them, and one of them was diagnosed with severe atrophy.

Out of 29 patients with retractile testes who completely responded to HCG, 20 individuals referred to the hospitals for their 3-month follow-ups. The testes were in the scrotum in 18 of them, while 2 cases had testes in the retractile position and their parents refused the surgery (Table 4).

\subsection{The One-year Follow-up:}

From 32 patients with non-palpable abdominal testes who responded to HCG therapy and had orchiopexy, 21 patients came back for their one-year follow-up visits. According to 
their ultrasonography results, the testes were smaller than the opposite testes in 18 of them and small nodule-like tissues with abnormal parenchyma in the topscrotal position were detected in 3 patients. Out of the 14 patients with non-palpable abdominal testes who had no response to HCG, 7 of them were admitted to the hospitals and laparoscopy was performed on them. Three of them had testes and underwent orchiopexy, two of them had small topscrotal testes, and one of them had sup.ing testis, which was detected as a very small nodular and atrophic tissue near the scrotum through ultrasound.

From 60 patients with inguinal testes who had responded to HCG therapy, 48 cases came back to the hospital to have their one-year follow-up visits. The testes were in the scrotum in 42 of them, top-scrotal in 4 of them, and beyond the external ring in the other 4 patients who underwent orchiopexy. From 26 patients who did not respond to HCG and orchiopexy was performed on them, 16 patients met their physician and the testes were in the scrotum in all of them; however, the testes were smaller than the normal size in 5 of the patients and were of the normal size but smaller than the opposite testes in 11 of them.

From the 39 patients with sup.ing testes who responded to HCG therapy, 28 of them visited the physician for the one-year follow-up meeting. The testes were located in the scrotum in 21 of them and the other 7 patients had top-scrotal testes. Among the 11 patients who did not respond to HCG and underwent orchiopexy, 7 of them immediately were visited by their physician and the testes were in the scrotum in all of them.

Ultimately, from 29 patients with retractile testes who completely responded to HCG therapy, 16 patients attended their one-year follow-up visits and the normal size testes were detected in the scrotum for all of them.

\section{DISCUSSION}

Based on the results, from 211 patients who received HCG as the treatment, testes descended to the inguinal canal or scrotum in 160 of them $(75.12 \%)$ four weeks after the first injection. The testes descended to the inguinal canal in $69.5 \%$ of all the 46 patients with non-palpable abdominal testes. Therefore, the need for performing laparoscopy on patients with abdominal testes decreased. From 86 patients with inguinal testes, the descent of testes to the scrotum occurred in 60 of them $(69.7 \%)$, which means orchiopexy is not required for these patients. Furthermore, 39 out of 50 patients (78\%) with sup.ing testes and $100 \%$ of the patients with retractile testes had the full descent of testis to the scrotum.

Based on the study by Nane I et al., $53 \%$ of abdominal testes, $19 \%$ of inguinal testes, and $100 \%$ of the testes located beyond the external ring, and $100 \%$ of suprascrotal testes descended. In the present study, the success rate of $69.5 \%$ was found for abdominal testes, $69.7 \%$ for inguinal testes, $78 \%$ for those located beyond the external ring, and $100 \%$ for suprascrotal testes. The differences between the results would be due to the different dosages of HCG in the studies. Moreover, cryptorchidism recurred in $16 \%$ of the cases during the follow-up periods and 12 of them underwent surgical treatment; while in the present study, $20-25 \%$ of the testes re- ascended and underwent orchiopexy during the follow-up periods.

The study by Piotrkucharski et al., demonstrated that HCG therapy led to the full descent of testes in $44.5 \%$ of the patients and improved the position of testes in $37.3 \%$ of them before performing orchiopexy [23]. In the present study, depending on the position of testes, $58 \%$ to $100 \%$ of them descended.

According to another study performed on 170 undescended testes, the best therapeutic response was observed when the position of testis was lower. HCG therapy was successful in $34.7 \%$ of the case, while it was more than $50 \%$ in the current study $[27,28]$.

The results of the study by Cheechakimy et al., demonstrated that $50 \%$ of bilateral cryptorchid testes and $32 \%$ of unilateral cryptorchid testes descended due to the treatment. In the present study, there was no comparison between the patients with bilateral and unilateral cryptorchidism as all the cases had unilateral undescended testes. The treatment was successful in $38.3 \%$ of the patients at first and $30.2 \%$ of them after the four-month follow up. In total, more than 50 of the cases responded to the treatment in this study and the treatment was more effective if the testes were located at the lower levels [29].

According to the study by Kjaer S. conducted on 121 cases with an average age of 3.6 years old who had 170 undescended testes, the treatment was successful in $34.7 \%$ of the cases. Similar to the current study, it was also realized that the treatment was more effective if the testes were located at lower levels [27].

Finally, in the present study, $79 \%$ of cryptorchid testes descended to a lower level and $61.7 \%$ of them descended to the scrotum due to HCG therapy.

\section{CONCLUSION}

More than $50 \%$ of the cases in all the groups responded to HCG therapy and the testes descended from the initial positions to lower levels. Consequently, the need for performing surgical procedures, laparoscopy and orchiopexy, on children with unilateral cryptorchidism decreased and they could be treated through a cost-effective and less invasive method. Considering the fact that recurrent undescended testes occurred in $20-25 \%$ of the patients, at least one-year follow-up of the patients is required to ensure outcomes of the treatment. Moreover, according to the results, HCG therapy would be more successful in patients with cryptorchidism if the testes are located at the lower levels. One of the most important results of this study is that $20 \%$ of abdominal undescended testes descended into the inguinal canal, which eliminated the need for invasive laparoscopy and two-stage surgery.

\section{ETHICAL APPROVAL AND CONSENT TO PARTICIPATE}

All procedures performed in the study that involved human participants were approved by the Ethics Committee of the Urology and Nephrology Research Center (UNRC) at the Shahid Beheshti University of Medical Sciences. 


\section{HUMAN AND ANIMAL RIGHTS}

Not applicable.

\section{CONSENT FOR PUBLICATION}

Not applicable.

\section{AVAILABILITY OF DATA AND MATERIALS}

The authors confirm that the data supporting the findings of this research are available within the article.

\section{FUNDING}

None.

\section{CONFLICT OF INTEREST}

The authors declare that there is no conflict of interest regarding the publication of this article.

\section{ACKNOWLEDGEMENTS}

Authors would like to acknowledge our colleagues in Labbafinejad, Milad and Torfeh Hospitals, Urology and Nephrology Research Center, and Shahid Beheshti University of Medical Sciences for their leading suggestions on this manuscript.

\section{REFERENCES}

[1] Francis X. Schneck MD and Mark F bellinger MD: Abnormalies of the testes and and scrotum and their Surgical Management-walsh, patrik C et al:" Campbells urology. 8th ed. USA: Sauners 2002; pp. 2353-70.

[2] Barthold JS, Gonzalez R. The epidemiology of congenital crytorchidism url 2003; 170: 2396-401.

[3] Paul JT. Male infertilityMC Graw-Hill, Smith's General urology. $16^{\text {th }}$ edition. 2004; p. 706

[4] Martin Ritze'n E. Undescended testes: a consensus on management. Eur J Endocrin 2008; 159: 87-90.

[5] Scorer CG, Farrington GH. Congenital of the Testis and Epididymis. New York: Appleton-Century- Crofts 1972

[6] Barthold JS, González R. The epidemiology of congenital cryptorchidism, testicular ascent and orchiopexy. J Urol 2003; $170(6$ Pt 1): 2396-401.

[http://dx.doi.org/10.1097/01.ju.0000095793.04232.d8] [PMID: 14634436]

[7] Thorup J, Haugen S, Kollin C, Lindahl S. ackgren GL, Nordenskjold A, Taskinen S. Surgical treatment of undescended testes. ActaPæ diatrica 2007; 96: 631-7.

[8] Meyrata B, Ramseyera P, Theintzd G, Burnandf B. Management of cryptorchidism in children:guidelines. SWISS MED WKLY 2008; 138(33-34): 492-8

[9] Rajfer J. Congenital anomalies of the testisand scrotum.Campbell's Urology, Walsh, PC,Retik, AB, Vaughan, ED. Philadelphia: WB Saunders Co 1998; p. 2172.

[10] Kirsch AJ, Escala J, Duckett JW, et al. Surgical management of the nonpalpable testis: the Children's Hospital of Philadelphia experience. J Urol 1998; 159(4): 1340-3.

[http://dx.doi.org/10.1016/S0022-5347(01)63613-9] [PMID: 9507881]

[11] Ferrer FA, McKenna PH. Current approaches to the undescended testis. Contemp Pediatr 2000; 17: 106.

[12] Adham IM, Agoulnik AI. Insulin-like 3 signalling in testicular descent. Int J Androl 2004; 27(5): 257-65.

[http://dx.doi.org/10.1111/j.1365-2605.2004.00481.x] [PMID: 15379965]
[13] Thorup J, Cortes D, Petersen BL. The incidence of bilateral cryptorchidism is increased and the fertility potential is reduced in sons born to mothers who have smoked during pregnancy. J Urol 2006; 176(2): 734-7

[http://dx.doi.org/10.1016/j.juro.2006.03.042] [PMID: 16813933]

[14] Damgaard IN, Skakkebaek NE, Toppari J, et al. Persistent pesticides in human breast milk and cryptorchidism. Environ Health Perspect 2006; 114(7): 1133-8.

[http://dx.doi.org/10.1289/ehp.8741] [PMID: 16835070]

[15] Park K, Choi H. An evolution of orchiopexy: historical aspect. Korean J Urol 2010; 51(3): 155-60

[http://dx.doi.org/10.4111/kju.2010.51.3.155] [PMID: 20414389]

[16] Carole Chedane, Hugues Puissant, Dominique Weil, StéphanieRouleauand RégisCoutant.Association between altered placental human chorionic gonadotrophin (hCG) production and the occurrence of cryptorchidism: a retrospectivestudy. BMC Pediatr 2014; 14: 191.

[http://dx.doi.org/10.1186/1471-2431-14-191]

[17] Zivkovic D, Bica DG, Hadziselimovic F. Effects of hormonal treatment on the contralateral descended testis in unilateral cryptorchidism. J Pediatr Urol 2006; 2(5): 468-72. [http://dx.doi.org/10.1016/j.jpurol.2005.11.007] [PMID: 18947658]

[18] Cromie WJ. Cryptorchidism and malignant testicular disease.Cryptorchidism: Management and Implications. New York: Springer- Verlag 1983; p. 83.

[http://dx.doi.org/10.1007/978-3-642-86020-1 7]

[19] Koivusalo A, Taskimen S, Rintala RJ. cryptorchidism in boys with congenital abdominal wall defect pediatr surg 1998; 13: 143 .

[20] YaseminÜstünsalih-İnan, Ergun Çetinkaya, SadiVidinlisan, AhmetÖrnek. Evaluation of low-dose hCG treatment for cryptorchidism. Turk J Pediatr 2006; 48: 228-31.

[21] Luque Mialdea R, Martín-Crespo Izquierdo R. [Laparoscopy in pediatric urology]. Arch Esp Urol 2002; 55(6): 737-47. [PMID: 12224172]

[22] Ghorbanpoor M, Amirzargar M, Derakhshanfar A, et al. The evaluation of laparoscopic orchiopexy on the treatment of nonpalpable undescended testis in ekbatan hospital of hamadan. Indian $\mathrm{J}$ Surg 2011; 19(2): 27-33

[23] Kucharski P, Niedzielski J. Neoadjuvant human Chorionic Gonadotropin (hCG) therapy may improve the position of undescended testis: a preliminary report. Cent European J Urol 2013; 66(2): 224-8 [PMID: 24579035]

[24] Bukowski TP, Sedberry S, Richardson B. Is human chorionic gonadotropin useful for identifying and treating nonpalpable testis? J Urol 2001; 165(1): 221-3.

[http://dx.doi.org/10.1097/00005392-200101000-00063] [PMID: 11125411]

[25] Miller OF, Stock JA, Cilento BG, McAleer IM, Kaplan GW, Kaplan W. Prospective evaluation of human chorionic gonadotropin in the differentiation of undescended testes from retractile testes. J Urol 2003; 169(6): 2328-31.

[http://dx.doi.org/10.1097/01.ju.0000065823.80051.bb] [PMID: 12771792]

[26] Ritzén EM. Undescended testes: a consensus on management. Eur Endocrinol 2008; 159(Suppl. 1): S87-90.

[http://dx.doi.org/10.1530/EJE-08-0181] [PMID: 18728121]

[27] Dunkel L, Taskinen S, Hovatta O, Tilly JL, Wikström S. Germ cell apoptosis after treatment of cryptorchidism with human chorionic gonadotropin is associated with impaired reproductive function in the adult. J Clin Invest 1997; 100(9): 2341-6.

[http://dx.doi.org/10.1172/JCI1 19773] [PMID: 9410913]

[28] Nane I, Ziylan O, Esen T, Kocak T, Ander H, Tellaloglu S. Primary gonadotropin releasing hormone and adjunctive human chorionic gonadotropin treatment in cryptorchidism: a clinical trial. Urology 1997; 49(1): 108-11.

[http://dx.doi.org/10.1016/S0090-4295(96)00359-7] [PMID: 9000196]

[29] BA CHEECHAK1MY WANI2 A HUSSAIN3 G HASSAN4Role of Human Chorionic Gonadotropin (HCG) Hormone in undescended testis - a prospective study in 100 children $\mathrm{J}$ indian assoc pediatr surg. 2004; 9 